\title{
A Rough Set Based Assessment of the Strategies to Reduce Greenhouse Gas Emissions: A Tanzanian Shipping Sector Perspective
}

\author{
Erick P. Massami ${ }^{1}$ and Benitha M. Myamba ${ }^{2}$ \\ ${ }^{1}$ Unit for Applied Mathematics, Dar es Salaam Institute of Technology, P.O. Box 2958, Dar es Salaam, Tanzania \\ ${ }^{2}$ Department of Logistics and Transport Studies, National Institute of Transport, P.O. Box 705, Dar es Salaam, Tanzania \\ Correspondence should be addressed to Erick P. Massami; epmassami@gmail.com
}

Received 27 October 2015; Revised 10 February 2016; Accepted 29 February 2016

Academic Editor: Panos Pardalos

Copyright (C) 2016 E. P. Massami and B. M. Myamba. This is an open access article distributed under the Creative Commons Attribution License, which permits unrestricted use, distribution, and reproduction in any medium, provided the original work is properly cited.

\begin{abstract}
The Greenhouse Gas (GHG) emissions due to transport operations have drastically increased in recent years. The sea transport in particular contributes 2.7 to 3 percent of $\mathrm{CO}_{2}$, a major component of GHG emissions globally. Numerous measures have been undertaken locally and internationally to alleviate the sea transport share of Greenhouse Gases. However, most of these measures will be fruitful if ship investors (e.g., ship owners and operators) would fully employ the GHG emission reduction strategies. Due to the scarcity of the statistical data in this respect, this study therefore presents a rough set synthetic assessment (RSSA) model to GHG emission abatement strategies in the Tanzanian shipping sector. The results of the assessment reveal that the Tanzanian shipping companies engaged in Cabotage trade are aware of the abatement strategies and moderately apply them.
\end{abstract}

\section{Introduction}

Scientific findings suggest that the Earth's average temperature is gradually increasing. More specifically, the Intergovernmental Panel on Climate Change (IPCC) has predicted a rise in global temperatures of between $1^{\circ}$ and $2^{\circ}$ Celsius by 2020 and between $2^{\circ}$ and $5^{\circ}$ Celsius by 2070 [1]. This phenomenon is a result of increased global emissions of Greenhouse Gases (GHGs) such as carbon dioxide $\left(\mathrm{CO}_{2}\right)$, methane $\left(\mathrm{CH}_{4}\right)$, nitrous oxide $\left(\mathrm{N}_{2} \mathrm{O}\right)$, and chlorofluorocarbon (CFC). $\mathrm{CO}_{2}$ is the major contributor and accounts for 77 percent of the GHG emissions [2]. Increased international awareness of this global temperature increase has led to considerable international effort, such as the United Nations Framework Convention on Climate Change (UNFCCC) and the Kyoto Protocol, to prevent climate change by attempting to reduce $\mathrm{CO}_{2}$ emissions.

Transportation, on the other hand, is the fastest growing major contributor to global climate change, accounting for 23 percent of energy-related $\mathrm{CO}_{2}$ emissions. Trends have shown substantial growth in Greenhouse Gases attributable to the transport sector in the majority of countries. The shipping industry in particular contributes 2.7 to 3 percent of about 400 million tons of $\mathrm{CO}_{2}$, a component of GHGs emissions worldwide [3]. As industrial as well as agricultural production is expected to increase in the future, the demand for shipping services will increase too. More specifically, $\mathrm{CO}_{2}$ emissions are forecast to increase by $150-250$ percent by 2050 , due to increased freight volumes [4]. With this consideration and the fact that the demand for shipping services is relatively high compared to other modes of transport mainly due to the economies of scale, the trend on $\mathrm{CO}_{2}$ emissions from the shipping industry is expected to increase at an increasing rate. Thus, effective strategies are necessary in order to combat this problem.

The literature proposes a number of available solution methods to individual ship owners, policy makers, and regulators for reducing GHG emissions from ships. The objective of this study is to assess the strategies employed by Tanzanian ship owners and ship operators (i.e., ship investors) to reduce GHG emissions from ship operations. The results will be a useful guide to the industry's players for taking corrective 
actions. The paper is structured as follows: in Section 2 we review the relevant literature; an overview of two-stage rough set synthetic assessment model is presented in Section 3; in Section 4 we apply rough set synthetic assessment (RSSA) model to GHG emissions in the Tanzanian shipping sector and in Section 5 we present conclusions.

\section{Survey of Previous Studies}

There are a number of studies on measures that reduce $\mathrm{CO}_{2}$ emissions and/or improve fuel efficiency of shipping and their cost effectiveness [5]. Crist [6] investigates the reduction potential of $\mathrm{GHG}$ emissions from international shipping. Corbett et al. [7] research the cost effectiveness of speed reductions on shipping emissions. The IMO [8] presents a proposal on prevention of air pollution from ships by establishing a vessel efficient system. Blasco et al. [9] use both qualitative and quantitative approaches to determine pollutant emissions from ships and their distribution and fate. Lindstad et al. [10] investigate the effects of economies of scale on the direct emissions and costs of maritime transport and find that 30 percent of a negative abatement cost per ton of $\mathrm{CO}_{2}$ can be reduced by replacing the existing fleet with larger vessels. Moreno-Gutiérrez et al. [11] apply nine methods for a comparative study to evaluate fuel consumption and emissions and find no significant differences between the methods. A study of the effects of speed reductions on the direct emissions and costs of maritime transport is investigated by Lindstad et al. [12] and shows that there is a substantial potential for reducing $\mathrm{CO}_{2}$ emissions from shipping operations. Maragkogianni and Papaefthimiou [13] estimate $\mathrm{NO}_{x}, \mathrm{SO}_{2}$, and $\mathrm{PM}_{2.5}$ emissions for cruise ships in the five busiest Greek ports for the year 2013 and find that anticipated health impacts of ship emissions can reach $€ 24.3$ million or $€ 5.3$ per passenger. Eyring et al. [14] present an assessment of the contribution of gaseous and particulate emissions from ocean going shipping to anthropogenic emissions and air quality. Zhou and Wang [15] propose application of Carbon Capture and Storage (CCS) on ships as an effective way to mitigate $\mathrm{CO}_{2}$ emissions while other low carbon shipping technologies are being developed in order to meet the IMO target of 20 percent reduction in $\mathrm{CO}_{2}$ emissions from marine activities by 2020 .

Armstrong [16] suggests optimization efforts in the areas of technical, commercial, and operational measures in order to increase fleet utilization and profitability while ensuring safety and reliability of service. Winnes et al. [17] quantify potential reductions of ships' emissions of GHG from efforts implemented by ports by using the Port of Gothenburg as a case study. Kitada and Ölcer [18] address the challenges facing managers in the shipping industry to implement energy efficient measures in ship operations and their roles of managing both people and technology under the fulfillment of their Corporate Social Responsibility (CSR). Chang and Wang [19] conduct a thorough assessment of available operating strategies to identify the approach to speed reduction that is best able to minimize costs and reduce the impact of shipping on the environment. Heitmann and Khalilian [20] propose various options suggested by the subsidiary body for scientific and technological advice of the UNFCCC for allocating $\mathrm{CO}_{2}$ emissions from international shipping to individual countries investigated. Lun et al. [21] propose and empirically validate an integrated model to study how various environmental governance mechanisms are enacted by shipping firms and their influence on shipping firms' environmental performance. Poulsen et al. [22] examine the relations between global value chain governance and environmental upgrading in shipping industry. Lindstad et al. [23] apply region-specific Global Warming Potential (GWP) to assess costs, emissions, and climate impact by freight shipping in the Arctic with main focus on the Northern Sea Route. Calleya et al. [24] propose the Ship Impact Model (SIM) to calculate the technical performance of a vessel with one or more Carbon Dioxide Reducing Technologies (CRTs) at an early design stage. Heitmann and Peterson [25] use a marginal abatement cost curve (MACC) and find that the shipping sector could always contribute to efficient global emission reductions and thus could always achieve global cost savings depending on the MACC assumed. Shi [26] examines whether it is necessary to adopt market based measures (MBMs) in furthering the reduction of shipping GHG emissions.

Numerous methods are proposed in the literature to assess GHG emissions from shipping. Chatzinikolaou and Ventikos [27] present a novel mathematical framework which incorporates the life cycle approach with the objective of providing a holistic assessment of air emissions for ocean going ships. Lu et al. [28] use a modified Kwon's method to select the optimum route for ship operators to increase energy efficiency and hence reduce GHG emissions in the shipping industry. Qi and Song [29] apply simulation-based stochastic approximation method to design an optimal vessel schedule in their liner shipping route to minimize the total expected fuel consumption and emissions on the liner schedule. Miola and Ciuffo [30] provide a critical analysis of the ship emission modelling approaches and the results highlight uncertainties from the different methods mainly connected with the sources of information that are used as inputs to the various studies.

The literature reveals that most of the studies propose measures that can reduce the GHG emissions and do not assess the employment of the suggested solution methods (i.e., operational, technical, and market based measures). No study assesses the applicability of these solution methods to the Tanzanian shipping industry whose shipping companies' characteristics (e.g., financial constraints and regulatory framework) are quite different from that of the maritime nations. This paper therefore assesses the applicability of the operational and technical measures to the Tanzanian shipping sector. In addition, most researchers and practitioners in decision making employ Analytical Hierarchy Process (AHP) approach and fuzzy set theory (FST) in ranking decision factors. For example, Lam and Lai [31] develop a decision support model which combines Analytical Network Process (ANP) with Quality Function Deployment (QFD) for shipping companies to attain environmental sustainability in their operations. Ren and Lützen [32] combine fuzzy Analytic Hierarchy Process (AHP) and VIKOR to select the 
most sustainable technology for emissions reduction from shipping. Mansouri et al. [33] present a review and future directions of multiobjective decision support to enhance environmental sustainability in shipping industry. As uncertainty is inevitable when assessing the attributes of GHG emission abatement measures in the Tanzanian shipping industry due to the vagueness and incompleteness of the data, the Rough Set Theory (RST) becomes the ideal approach [34]. Moreover, the rough set approach is flexible and can accommodate any finite sets of objects and indicators. The main advantages of the RST include the following [35]:

(i) It does not need any preliminary or additional information about data like grade of membership in the fuzzy set theory.

(ii) The weight of the factor is not assigned subjectively like in the AHP method.

(iii) It is easy to understand.

(iv) It offers straightforward interpretation of obtained results.

(v) It allows reducing original data, that is, to find minimal sets of data with the same knowledge as in the original data.

(vi) It provides efficient methods, algorithms, and tools for finding hidden patterns in data.

(vii) It allows evaluating the significance of data.

\section{Overview of Rough Sets}

Rough Set Theory (RST) was introduced by Zdzislaw Pawlak in 1982. The RST is useful for reasoning about knowledge of objects represented by attributes (i.e., features). Some of the fundamental concepts under the RST are approximation space, information system, decision system, approximation of sets, dependency of attributes, and significance of attributes. Approximation space is a pair $(U, R)$, where $U$ is a nonempty finite set called the universe and $R$ is an equivalence relation defined on $U$. Information system is a pair $S=(U, A)$, where $U$ is a nonempty finite set called the universe and $A$ is a nonempty finite set of attributes; that is, $a: U \rightarrow$ $V_{a}, a \in A$, where set $V_{a}$ is called the value set of $a$. Decision system (decision table) is a special case of information system composed of condition and decision attributes; that is, $S=$ $(U, A=C \cup\{d\})$, where attributes in $C$ are called condition attributes and $d$ is a designated attribute called the decision attribute. Approximation of sets is built on three concepts: lower approximation, upper approximation, and boundary region. Let $S=(U, R)$ be an approximation space and let $X$ be a subset of $U$.

The lower approximation of a set $(\underline{R X})$ is union of all granules which are entirely included in the set; that is,

$$
\underline{R} X=\left\{x \in U \mid[x]_{R} \subseteq X\right\} .
$$

The upper approximation of a set $(\bar{R} X)$ is union of all granules which have nonempty intersection with the set; that is,

$$
\bar{R} X=\left\{x \in U \mid\left([x]_{R} \cap X\right) \neq \emptyset\right\} .
$$

The boundary region of a set $\left(\mathrm{BN}_{R}(X)\right)$ is the difference between the upper and the lower approximation of the set; that is,

$$
\left(\mathrm{BN}_{R}(X)\right)=\bar{R} X-\underline{R} X .
$$

Set $X$ is rough in $S$ provided

$$
(\bar{R} X-\underline{R} X) \neq \emptyset .
$$

Suppose $S=(U, A), B \subseteq A$, and $X \subseteq U$.

Accuracy of approximation $\left(\alpha_{B}(X)\right)$ is the ratio of the lower approximation of a set to the upper approximation of the set; that is,

$$
\alpha_{B}(X)=\frac{|\underline{B}(X)|}{|\bar{B}(X)|}, \quad 0 \leq \alpha_{B}(X) \leq 1 .
$$

$|X|$ denotes the cardinality of $X \neq \emptyset$.

If $\alpha_{B}(X)=1$ then $X$ is crisp with respect to $B$ (i.e., $X$ is precise with respect to $B$ ).

If $\alpha_{B}(X)<1$ then $X$ is rough with respect to $B$ (i.e., $X$ is vague with respect to $B$ ).

Dependency of Condition and Decision Attributes. Let $D$ and $C$ be subsets of $A$. We say that $D$ depends on $C$ in degree $k(0 \leq$ $k \leq 1)$, denoted by $C \rightarrow D_{k}$, if

$$
k=\gamma(C, D)=\frac{\left|\operatorname{POS}_{C}(D)\right|}{|U|},
$$

where $\operatorname{POS}_{C}(D)=\bigcup_{X \in U / D} \underline{C}(X)$, called a positive region of partition $U / D$ with respect to $C$, is the set of all elements of $U$ that can be uniquely classified into blocks of partition $U / D$, by means of $C$. Obviously,

$$
k=\gamma(C, D)=\sum_{X \in U / D} \frac{|\underline{C}(X)|}{|U|} .
$$

If $k=1$ we say that $D$ depends totally on $C$, and if $k<1$, we say that $D$ depends partially on $C$.

Dispensable and Indispensable Attributes. Let $S=(U, A=$ $C \cup D$ ) be a decision system (i.e., decision table). Suppose $C_{j} \subseteq C$. Attribute $C_{j}$ is dispensable in $S$ if $\operatorname{POS}_{C}(D)=$ $\operatorname{POS}_{C-C_{j}}(D)$. Otherwise, $C_{j}$ is indispensable. Decision system $S$ is independent if all attributes in $C$ are indispensable.

Significance of Attributes. The significance of attributes enables us to express how important an attribute in an information table is by assigning a real number from the closed interval $[0,1]$ (i.e., $a \in[0,1], a \in \mathbb{R}$ ). The significance of an attribute $C_{j}$ in a decision table $T=(U, C \cup\{d\}$ ) (with the decision set $D$ ) can be evaluated by measuring the effect of removing of attribute $C_{j} \subseteq C$ from attribute set $C$ on the positive region defined by table $T$. Number $\gamma(C, D)$ expresses the degree of dependency between attribute sets $C$ and $D$ or accuracy of approximation of $U / D$ by $C$.

We can determine how coefficient $\gamma(C, D)$ changes when removing an attribute set $C_{j}$, that is, what the difference is 
between $\gamma(C, D)$ and $\gamma\left(C-C_{j}, D\right)$. We can normalize the difference and define the significance of attribute set $C_{j}$ as

$$
\alpha\left(C_{j}\right)=\frac{\gamma(C, D)-\gamma\left(C-C_{j}, D\right)}{\gamma(C, D)} .
$$

This mathematical relation also can be written as

$$
\alpha\left(C_{j}\right)=1-\frac{\gamma\left(C-C_{j}, D\right)}{\gamma(C, D)} .
$$

The next section describes in brief the two-stage rough set based modelling procedure for assessing the strategies to reduce GHG emissions. Since multiple primary and secondary factors are considered for assessment to make a decision, a process is called a two-stage rough set synthetic assessment model.

\section{Description of Two-Stage Rough Set Synthetic Assessment Model}

A rough set based assessment procedure for the two-stage synthetic model with a number of prime factors and subfactors is as follows.

4.1. Classifying of Prime Factors and Subfactors. Let $U$ and $u_{i}$ be sets of prime factors and subfactors, respectively. Now $U=$ $\left\{u_{i}\right\}, i \in\{1,2, \ldots, I\}$, and $u_{i}=\left\{u_{i j}\right\}, i \in\{1,2, \ldots, I\}, j \in$ $\{1,2, \ldots, J\}$.

4.2. Setting Up the Weight Set. Let $A=\left\{u_{k}\right\}, k \in\{1,2, \ldots, I\}$, be the set of weighted prime factors and let $A_{i}=\left\{u_{i j}\right\}, i \in$ $\{1,2, \ldots, I\}, j \in\{1,2, \ldots, J\}$, be the set of weighted subfactors. These weights are determined by rough set approach (RSA).

Each prime factor and subfactor weight fulfills the following properties:

$$
\begin{aligned}
& \sum_{k=1}^{I} u_{k}=1, \quad u_{k} \geq 0 ; \\
& \sum_{j=1}^{J} u_{i j}=1, \\
& u_{i j} \geq 0, \quad i \in\{1,2, \ldots, I\}, j \in\{1,2, \ldots, J\} .
\end{aligned}
$$

4.3. Setting Up the Assessment Set. Let an assessment set be $E=\left\{E_{i}\right\}$ where $E_{i}, i \in\{1,2, \ldots, I\}$, is a possible assessment result for the objective of investigation (i.e., assessment linguistic term, e.g., Very high, Low). Essentially, a two-stage rough set assessment (RSA) is a product of prime factor weight set and one-stage rough set synthetic assessment (RSSA).

4.4. 1st Stage of Two-Stage Rough Set Synthetic Assessment. The influence of each subfactor on the applicability level of the ship investors' strategies to reduce GHG emissions enables us to construct an assessment matrix of subfactors corresponding to factor $i, R_{i}, i \in\{1,2, \ldots, I\}$; the respective set of one-stage RSSA (i.e., $i$ th single factor rough set based assessment matrix) is

$$
E_{i}=A_{i} \cdot R_{i}, \quad i \in\{1,2, \ldots, I\} .
$$

4.5. 2nd Stage of Two-Stage Rough Set Synthetic Assessment. When we transpose the single factor rough set based assessment matrix we get $E^{T}=\left[E_{i}\right]^{T}, i \in\{1,2, \ldots, I\}$. Now the set of two-stage RSSA is $B=A \cdot E^{T}$. The expected applicability level is given by $E[x]=\sum_{\forall x} x P(X=x)$, where each $x$ and $P(X=x)$, respectively, represent an assessment value corresponding to a particular linguistic term, for example, Very low, and its probability of occurrence.

\section{Reduction of GHG Emissions Based on the Rough Set Synthetic Assessment Model}

We first establish the reduction strategies of $\mathrm{CO}_{2}$ emissions from the shipping industry to be used as inputs into the RSSA model.

5.1. Measures for Reducing $\mathrm{CO}_{2}$ Emissions from the Shipping Industry. DNV [36] presents the following emission reduction measures available to the shipping industry. Technical measures, on the one hand, aim at either reducing the power requirement to the engines or improving fuel efficiency. Examples of these measures are fuels and power sources. The alternatives range from supplementary measures (e.g., wind and solar power) to a complete switch of fuel (e.g., to gas, biodiesel, or nuclear fuel). However, these measures require significant investments up front, both onboard and in new infrastructure. As such, most ship investors complement these measures with operational measures. Operational measures, on the other hand, relate to the way in which the ship is maintained and operated and include measures such as optimized trim and ballasting, hull and propeller cleaning, better engine maintenance, and optimized weather routing and scheduling. Generally, these measures have low investment needs and moderate operating costs. However, the implementation of many of these measures requires execution of programs involving changes in management and training.

The technical and operational measures are also proposed by the IMO [37] which gives a relatively extensive list of fifty (50) energy efficiency improvement measures. In addition to these GHG emission abatement measures, market based measures are proposed by some studies. However, these measures are disregarded by this study due to their difficulty in implementation. Thus, this study is based on the technical and operational measures that seem to be practical in the Tanzanian shipping industry. Below is a brief description of components of GHG emission abatement measures, that is, technical and operational measures. Each of the proposed prime abatement measures (i.e., first-level measures) is composed of a number of submeasures (i.e., second-level measures). 
5.1.1. Operational Measures $\left(C_{1}\right)$. Propeller polishing $\left(C_{11}\right)$ : propeller surfaces can be cleaned to reduce roughness and the accumulation of organic materials. Autopilot upgrade/adjustment $\left(C_{12}\right)$ : adjusting the autopilot to the route and the operation area prevents unnecessary use of the rudder for keeping the ship on course. Weather routing $\left(C_{13}\right)$ : there are weather routing services available that help to optimize the route a ship takes, given the corresponding weather conditions; reduction of travel time leads to a reduction of fuel consumption. Hull cleaning $\left(C_{14}\right)$ : by reducing the frictional resistance of a hull, consumption of bunker fuel and thus emissions of $\mathrm{CO}_{2}$ can be reduced; this is often the outcome of a hull resistance management program. One way of reducing the frictional resistance is to enhance the smoothness of a hull by means of coatings that prevent/reduce fouling.

5.1.2. Technical Measures $\left(C_{2}\right)$. Water flow optimization of hull openings $\left(C_{21}\right)$ : the water flow disturbances from hull openings can be reduced by installing scallops or grids. Propeller upgrade $\left(C_{22}\right)$ : energy losses can occur at the top of the propeller blades from water escaping from the high pressure side to the low pressure side. Both a nozzle, that is, a ring around the propeller, and winglets at the tip can reduce these energy losses. Air lubrication $\left(C_{23}\right)$ : frictional resistance of a vessel's hull surface can be reduced by a so-called air cavity system. Such a system has to be integrated into the flat bottom part of a vessel. Hull coating $\left(C_{24}\right)$ : by reducing the frictional resistance of a hull, consumption of bunker fuel can be reduced. One way of reducing the frictional resistance is to enhance the smoothness of a hull by means of coatings that prevent/reduce fouling. Wind power $\left(C_{25}\right)$ : with a kite that is attached to the bow of a ship, wind energy can be used to substitute power of the ship engines. Waste heat recovery/reduction $\left(C_{26}\right)$ : with a waste heat recovery (WHR) system the waste heat of the engines can be used to drive turbines for electricity production, leading to less fuel consumption by the auxiliary engines. Design speed reduction $\left(C_{27}\right)$ : emission savings can be reaped when a vessel is slow steamed. The design speed can be reduced by, on the one hand, derating the main engine or, on the other hand, by using less powerful engines or engines that can deactivate cylinders (so as to have available reserve power for safety considerations). Main engine adjustment/tuning $\left(C_{28}\right)$ : in main tuning, the most commonly used load ranges have to be determined and then the main engine is optimized for operation at that load. This measure requires a different engine mapping and entails changes in cam profiles and injection timing. Speed control of pumps and fans $\left(C_{29}\right)$ : this reduces onboard power demand by using pumps and fans at variable speed, according to the actual need. High-efficient (i.e., energy saving) lighting $\left(C_{210}\right)$ : the usage of low energy lighting is useful for reducing the power demand onboard. Solar power $\left(C_{211}\right)$ : solar panels can be used in place of the conventional power sources to deliver electricity for the onboard power demand and hence reduce $\mathrm{CO}_{2}$ emissions from ships.

5.2. Weight Determination of Influential Factors. The general procedure for weight determination using rough set goes through the following four steps: Step one involves the formulation of a decision table consisting of objects, condition attributes, and decision attribute. Step two involves the deletion of redundant attributes and retaining of the key attributes to form the simplified decision table. Step three involves the calculation of the significance of each condition attribute in the simplified decision table. Step four involves the computation of the weight of each condition attribute by normalizing the significance of the attributes. However, our procedure does not involve step two as we want to see the influence (i.e., contribution) of each condition attribute (i.e., abatement measure) in its corresponding factor set and/or subfactor set. The contribution of each factor and/or subfactor can be determined using the following mathematical relations for indispensable and dispensable attributes.

5.2.1. Indispensable Attribute. Let $C_{j}$ be a conditional attribute and $\alpha\left(C_{j}\right)$ its significance in the attribute set and then the weight of $C_{j}$ is given by

$$
W_{C_{j}}=\frac{\alpha\left(C_{j}\right)}{\sum_{k=1}^{K} \alpha\left(C_{k}\right)}, j \in\{1,2, \ldots, J\} .
$$

5.2.2. Dispensable Attribute. If $\exists C_{j} \subseteq C, \operatorname{POS}_{C_{-} C_{j}}(D)=$ $\operatorname{POS}_{C}(D)$, a decision system (i.e., decision table) is not independent and $\gamma\left(C-C_{j}, D\right)=\gamma(C, D)$ which in turn gives $\alpha\left(C_{j}\right)=0$. This may give unsatisfactory results as the influence of each factor or subfactor cannot be revealed. Whenever a relatively large number of factors or subfactors satisfy such a condition, it is useful to compute the weight of $C_{j}$ by

$$
W_{C_{j}}=\frac{\gamma\left(C_{j}, D\right)}{\sum_{k=1}^{K} \gamma\left(C_{k}, D\right)}, \quad j \in\{1,2, \ldots, J\} .
$$

5.3. Computational Results of GHG Emissions Based on Rough Set Theory. A sample of eight Tanzanian companies involved in coastal shipping (i.e., Cabotage trade) was chosen randomly and asked for either company's chief engineer or company's captain to fill in a survey questionnaire. Each evaluator was given enough time to think critically about their company's policy towards GHG emission abatement measures. The assessment results are as given in decision Tables 1, 3, and 5, whereas the weighted factors and/or subfactors are presented in Tables 2, 4, and 6.

Note on Table 1. $P_{i}$ is company i's corporate policy (i.e., strategy) on GHG emission abatement measure:

$$
\begin{aligned}
U & =\left\{P_{1}, P_{2}, P_{3}, P_{4}, P_{5}, P_{6}, P_{7}, P_{8}\right\} \\
U \backslash C & =\left\{\left\{P_{1}, P_{3}, P_{4}, P_{8}\right\},\left\{P_{2}, P_{7}\right\},\left\{P_{5}\right\},\left\{P_{6}\right\}\right\} \\
U \backslash C_{1} & =U \backslash C-C_{2} \\
& =\left\{\left\{P_{1}, P_{3}, P_{4}, P_{5}, P_{8}\right\},\left\{P_{2}, P_{6}, P_{7}\right\}\right\} \\
U \backslash C_{2} & =U \backslash C-C_{1} \\
& =\left\{\left\{P_{1}, P_{2}, P_{3}, P_{4}, P_{7}, P_{8}\right\},\left\{P_{5}\right\},\left\{P_{6}\right\}\right\} \\
U \backslash D & =\left\{\left\{P_{1}, P_{4}, P_{8}\right\},\left\{P_{2}, P_{3}, P_{5}, P_{7}\right\},\left\{P_{6}\right\}\right\} .
\end{aligned}
$$


TABLE 1: Rough set based assessment results for prime operational and technical abatement measures on GHG emissions.

\begin{tabular}{lccc}
\hline $\begin{array}{l}\text { Company } \\
\text { policy }(U)\end{array}$ & $\begin{array}{c}\text { Operational } \\
\text { measure }\left(C_{1}\right)\end{array}$ & $\begin{array}{c}\text { Technical } \\
\text { measure }\left(C_{2}\right)\end{array}$ & $\begin{array}{c}\text { Decision } \\
(D)\end{array}$ \\
\hline$P_{1}$ & $\mathrm{M}$ & $\mathrm{L}$ & $\mathbf{L}$ \\
$P_{2}$ & $\mathrm{H}$ & $\mathrm{L}$ & $\mathbf{M}$ \\
$P_{3}$ & $\mathrm{M}$ & $\mathrm{L}$ & $\mathbf{M}$ \\
$P_{4}$ & $\mathrm{M}$ & $\mathrm{L}$ & $\mathbf{L}$ \\
$P_{5}$ & $\mathrm{M}$ & $\mathrm{M}$ & $\mathbf{M}$ \\
$P_{6}$ & $\mathrm{H}$ & $\mathrm{H}$ & $\mathbf{H}$ \\
$P_{7}$ & $\mathrm{H}$ & $\mathrm{L}$ & $\mathbf{M}$ \\
$P_{8}$ & $\mathrm{M}$ & $\mathrm{L}$ & $\mathbf{L}$ \\
\hline
\end{tabular}

TABLE 2: The significance and weight for the prime abatement measures.

\begin{tabular}{lcc}
\hline Factor & Significance & Weight \\
& $\alpha\left(C_{j}\right)$ & $W_{C_{j}}$ \\
\hline$C_{1}$ & 0.71 & 0.55 \\
$C_{2}$ & 0.57 & 0.45 \\
\hline
\end{tabular}

TABLE 3: Rough set based assessment results of company's policy on suboperational abatement measures for GHG emissions.

\begin{tabular}{lccccc}
\hline Company's policy $(U)$ & $C_{11}$ & $C_{12}$ & $C_{13}$ & $C_{14}$ & Decision $(D)$ \\
\hline$P_{1}$ & $\mathrm{H}$ & $\mathrm{H}$ & $\mathrm{L}$ & $\mathrm{H}$ & $\mathbf{M}$ \\
$P_{2}$ & $\mathrm{~V}$ & $\mathrm{H}$ & $\mathrm{M}$ & $\mathrm{H}$ & $\mathbf{H}$ \\
$P_{3}$ & $\mathrm{H}$ & $\mathrm{M}$ & $\mathrm{M}$ & $\mathrm{H}$ & $\mathbf{M}$ \\
$P_{4}$ & $\mathrm{~V}$ & $\mathrm{~N}$ & $\mathrm{~L}$ & $\mathrm{H}$ & $\mathbf{M}$ \\
$P_{5}$ & $\mathrm{H}$ & $\mathrm{L}$ & $\mathrm{N}$ & $\mathrm{H}$ & $\mathbf{M}$ \\
$P_{6}$ & $\mathrm{~V}$ & $\mathrm{H}$ & $\mathrm{L}$ & $\mathrm{V}$ & $\mathbf{H}$ \\
$P_{7}$ & $\mathrm{~V}$ & $\mathrm{H}$ & $\mathrm{H}$ & $\mathrm{H}$ & $\mathbf{H}$ \\
$P_{8}$ & $\mathrm{~N}$ & $\mathrm{H}$ & $\mathrm{H}$ & $\mathrm{H}$ & $\mathbf{M}$ \\
\hline
\end{tabular}

TABLE 4: The degree of dependency and weight for the suboperational abatement measures.

\begin{tabular}{lcc}
\hline Subfactor & $\begin{array}{c}\text { Degree of dependence } \\
\gamma\left(C_{i j}, D\right)\end{array}$ & $\begin{array}{c}\text { Weight } \\
W_{C_{i j}}\end{array}$ \\
\hline$C_{11}$ & 0.88 & 0.41 \\
$C_{12}$ & 0.38 & 0.18 \\
$C_{13}$ & 0.12 & 0.06 \\
$C_{14}$ & 0.75 & 0.35 \\
\hline
\end{tabular}

TABLE 5: Rough set based assessment results of company's policy on subtechnical abatement measures for GHG emissions.

\begin{tabular}{ccccccccccccc}
\hline$U$ & $C_{21}$ & $C_{22}$ & $C_{23}$ & $C_{24}$ & $C_{25}$ & $C_{26}$ & $C_{27}$ & $C_{28}$ & $C_{29}$ & $C_{210}$ & $C_{211}$ & $D$ \\
\hline$P_{1}$ & $\mathrm{~N}$ & $\mathrm{H}$ & $\mathrm{N}$ & $\mathrm{H}$ & $\mathrm{N}$ & $\mathrm{N}$ & $\mathrm{M}$ & $\mathrm{N}$ & $\mathrm{H}$ & $\mathrm{H}$ & $\mathrm{N}$ & $\mathrm{L}$ \\
$P_{2}$ & $\mathrm{~N}$ & $\mathrm{H}$ & $\mathrm{N}$ & $\mathrm{V}$ & $\mathrm{N}$ & $\mathrm{N}$ & $\mathrm{V}$ & $\mathrm{H}$ & $\mathrm{M}$ & $\mathrm{N}$ & $\mathrm{N}$ & $\mathrm{L}$ \\
$P_{3}$ & $\mathrm{~N}$ & $\mathrm{H}$ & $\mathrm{N}$ & $\mathrm{H}$ & $\mathrm{N}$ & $\mathrm{M}$ & $\mathrm{M}$ & $\mathrm{N}$ & $\mathrm{H}$ & $\mathrm{M}$ & $\mathrm{N}$ & $\mathrm{L}$ \\
$P_{4}$ & $\mathrm{~N}$ & $\mathrm{H}$ & $\mathrm{N}$ & $\mathrm{H}$ & $\mathrm{N}$ & $\mathrm{N}$ & $\mathrm{H}$ & $\mathrm{H}$ & $\mathrm{H}$ & $\mathrm{L}$ & $\mathrm{N}$ & $\mathrm{L}$ \\
$P_{5}$ & $\mathrm{~N}$ & $\mathrm{H}$ & $\mathrm{N}$ & $\mathrm{H}$ & $\mathrm{N}$ & $\mathrm{N}$ & $\mathrm{M}$ & $\mathrm{H}$ & $\mathrm{H}$ & $\mathrm{H}$ & $\mathrm{N}$ & $\mathbf{M}$ \\
$P_{6}$ & $\mathrm{~V}$ & $\mathrm{~V}$ & $\mathrm{~N}$ & $\mathrm{~V}$ & $\mathrm{~N}$ & $\mathrm{M}$ & $\mathrm{V}$ & $\mathrm{V}$ & $\mathrm{V}$ & $\mathrm{V}$ & $\mathrm{N}$ & $\mathrm{H}$ \\
$P_{7}$ & $\mathrm{~N}$ & $\mathrm{H}$ & $\mathrm{N}$ & $\mathrm{N}$ & $\mathrm{N}$ & $\mathrm{N}$ & $\mathrm{H}$ & $\mathrm{N}$ & $\mathrm{H}$ & $\mathrm{N}$ & $\mathrm{N}$ & $\mathrm{L}$ \\
$P_{8}$ & $\mathrm{~N}$ & $\mathrm{~N}$ & $\mathrm{~N}$ & $\mathrm{H}$ & $\mathrm{N}$ & $\mathrm{N}$ & $\mathrm{H}$ & $\mathrm{N}$ & $\mathrm{H}$ & $\mathrm{H}$ & $\mathrm{N}$ & $\mathrm{L}$ \\
\hline
\end{tabular}

TABLE 6: The degree of dependency and weight for the subtechnical abatement measures.

\begin{tabular}{lcc}
\hline Subfactor & $\begin{array}{c}\text { Degree of dependency } \\
\gamma\left(C_{i j}, D\right)\end{array}$ & $\begin{array}{c}\text { Weight } \\
W_{C_{i j}}\end{array}$ \\
\hline$C_{21}$ & 0.38 & 0.05 \\
$C_{22}$ & 0.38 & 0.05 \\
$C_{23}$ & 1.00 & 0.15 \\
$C_{24}$ & 0.25 & 0.04 \\
$C_{25}$ & 1.00 & 0.15 \\
$C_{26}$ & 0.25 & 0.04 \\
$C_{27}$ & 0.62 & 0.09 \\
$C_{28}$ & 0.75 & 0.11 \\
$C_{29}$ & 0.38 & 0.06 \\
$C_{210}$ & 0.75 & 0.11 \\
$C_{211}$ & 1.00 & 0.15 \\
\hline
\end{tabular}

Using (3) and (10) we get

$$
\begin{aligned}
\underline{C}\left(\left\{P_{1}, P_{4}, P_{8}\right\}\right) & =\left\{P_{1}, P_{4}, P_{8}\right\}, \\
\underline{C}\left(\left\{P_{2}, P_{3}, P_{5}, P_{7}\right\}\right) & =\left\{P_{2}, P_{5}, P_{7}\right\}, \\
\underline{C}\left(\left\{P_{6}\right\}\right) & =\left\{P_{6}\right\} \\
\gamma(C, D) & =\sum_{X \in U / D} \frac{|\underline{C}(X)|}{|U|}=\frac{7}{8} \\
\underline{C_{1}}\left(\left\{P_{1}, P_{4}, P_{8}\right\}\right) & =\left\{P_{1}, P_{4}, P_{8}\right\}, \\
\underline{C_{1}}\left(\left\{P_{2}, P_{3}, P_{5}, P_{7}\right\}\right) & =\emptyset, \\
\underline{C_{1}}\left(\left\{P_{6}\right\}\right) & =\emptyset
\end{aligned}
$$

$$
\begin{aligned}
\gamma\left(\underline{C_{1}}, D\right) & =\sum_{X \in U / D} \frac{\left|\underline{C_{1}}(X)\right|}{|U|}=\frac{3}{8} \\
\underline{C_{2}}\left(\left\{P_{1}, P_{4}, P_{8}\right\}\right) & =\emptyset, \\
\underline{C_{2}}\left(\left\{P_{2}, P_{3}, P_{5}, P_{7}\right\}\right) & =\left\{P_{5}\right\}, \\
\underline{C_{2}}\left(\left\{P_{6}\right\}\right) & =\left\{P_{6}\right\} \\
\gamma\left(\underline{C_{2}}, D\right) & =\sum_{X \in U / D} \frac{\left|C_{2}(X)\right|}{|U|}=\frac{2}{8}=\frac{1}{4} .
\end{aligned}
$$

Using (9) and (12) we get the significance and weight for each of the two condition attributes as indicated in Table 2.

Table 2 shows that Tanzanian shipping investors apply more operational measures compared to technical measures for reducing GHG emissions from shipping operations. Thus, these investors are relatively good at maintaining and operating vessels. In addition, this situation could be caused by relatively low financial resources that they have to support the technical abatement measures. 
The proposed operational measure constitutes a number of subabatement measures and its assessment is as shown in Table 3.

Note on Table 3. $C_{11}$ is propeller polishing, $C_{12}$ is autopilot upgrade/adjustment, $C_{13}$ is weather routing, and $C_{14}$ is hull cleaning:

$$
\begin{aligned}
& C=\left\{C_{11}, C_{12}, C_{13}, C_{14}\right\} ; \\
& C-C_{11}=\left\{C_{12}, C_{13}, C_{14}\right\} \text {; } \\
& C-C_{12}=\left\{C_{11}, C_{13}, C_{14}\right\} \text {; } \\
& C-C_{13}=\left\{C_{11}, C_{12}, C_{14}\right\} \text {; } \\
& C-C_{14}=\left\{C_{11}, C_{12}, C_{13}\right\} \\
& U \backslash C \\
& =\left\{\left\{P_{1}\right\},\left\{P_{2}\right\},\left\{P_{3}\right\},\left\{P_{4}\right\},\left\{P_{5}\right\},\left\{P_{6}\right\},\left\{P_{7}\right\},\left\{P_{8}\right\}\right\} \\
& U \backslash C_{11}=\left\{\left\{P_{1}, P_{3}, P_{5}\right\},\left\{P_{2}, P_{4}, P_{6}, P_{7}\right\},\left\{P_{8}\right\}\right\} \\
& U \backslash C_{12}=\left\{\left\{P_{1}, P_{2}, P_{6}, P_{7}, P_{8}\right\},\left\{P_{3}\right\},\left\{P_{4}\right\},\left\{P_{5}\right\}\right\} \\
& U \backslash C_{13}=\left\{\left\{P_{1}, P_{4}, P_{6}\right\},\left\{P_{2}, P_{3}\right\},\left\{P_{5}\right\},\left\{P_{7}, P_{8}\right\}\right\} \\
& U \backslash C_{14}=\left\{\left\{P_{1}, P_{2}, P_{3}, P_{4}, P_{5}, P_{7}, P_{8}\right\},\left\{P_{6}\right\}\right\} \\
& U \backslash C-C_{11} \\
& =\left\{\left\{P_{1}\right\},\left\{P_{2}\right\},\left\{P_{3}\right\},\left\{P_{4}\right\},\left\{P_{5}\right\},\left\{P_{6}\right\},\left\{P_{7}, P_{8}\right\}\right\} \\
& U \backslash C-C_{12} \\
& =\left\{\left\{P_{1}\right\},\left\{P_{2}\right\},\left\{P_{3}\right\},\left\{P_{4}\right\},\left\{P_{5}\right\},\left\{P_{6}\right\},\left\{P_{7}\right\},\left\{P_{8}\right\}\right\} \\
& U \backslash C-C_{13} \\
& =\left\{\left\{P_{1}\right\},\left\{P_{2}, P_{7}\right\},\left\{P_{3}\right\},\left\{P_{4}\right\},\left\{P_{5}\right\},\left\{P_{6}\right\},\left\{P_{8}\right\}\right\} \\
& U \backslash C-C_{14} \\
& =\left\{\left\{P_{1}\right\},\left\{P_{2}\right\},\left\{P_{3}\right\},\left\{P_{4}\right\},\left\{P_{5}\right\},\left\{P_{6}\right\},\left\{P_{7}\right\},\left\{P_{8}\right\}\right\} \\
& U \backslash D=\left\{\left\{P_{1}, P_{3}, P_{4}, P_{5}, P_{8}\right\},\left\{P_{2}, P_{6}, P_{7}\right\}\right\} .
\end{aligned}
$$

Using (1) we find that

$$
\begin{aligned}
\bigcup_{\forall x \in D} \underline{C-C_{1 t}}(x) & =\bigcup_{\forall x \in D} \underline{C}(x) \\
& =\left\{P_{1}, P_{2}, P_{3}, P_{4}, P_{5}, P_{6}, P_{7}, P_{8}\right\},
\end{aligned}
$$

$\forall t \in\{2,3,4\}$.

Thus,

$$
\gamma\left(C-C_{1 t}, D\right)=\gamma(C, D) \longrightarrow \alpha\left(C_{1 t}\right)=0,
$$$$
\forall t \in\{2,3,4\} \text {. }
$$

$\left.C_{211}\right\}$;

$$
C-C_{23}=\left\{C_{21}, C_{22}, C_{24}, C_{25}, C_{26}, C_{27}, C_{28}, C_{29}, C_{210}\right. \text {, }
$$$$
\left.C_{211}\right\} \text {; }
$$

$$
C-C_{24}=\left\{C_{21}, C_{22}, C_{23}, C_{25}, C_{26}, C_{27}, C_{28}, C_{29}, C_{210}\right. \text {, }
$$$$
\left.C_{211}\right\} \text {; }
$$$$
C-C_{25}=\left\{C_{21}, C_{22}, C_{23}, C_{24}, C_{26}, C_{27}, C_{28}, C_{29}, C_{210}\right. \text {, }
$$$$
\left.C_{211}\right\} \text {; }
$$$$
C-C_{26}=\left\{C_{21}, C_{22}, C_{23}, C_{24}, C_{25}, C_{27}, C_{28}, C_{29}, C_{210}\right. \text {, }
$$$$
\left.C_{211}\right\} \text {; }
$$$$
C-C_{27}=\left\{C_{21}, C_{22}, C_{23}, C_{24}, C_{25}, C_{26}, C_{28}, C_{29}, C_{210}\right. \text {, }
$$$$
\left.C_{211}\right\} \text {; }
$$$$
C-C_{28}=\left\{C_{21}, C_{22}, C_{23}, C_{24}, C_{25}, C_{26}, C_{27}, C_{29}, C_{210}\right. \text {, }
$$$$
\left.C_{211}\right\} \text {; }
$$

$$
\begin{aligned}
C-C_{29} & =\left\{C_{21}, C_{22}, C_{23}, C_{24}, C_{25}, C_{26}, C_{27}, C_{28}, C_{210},\right. \\
\left.C_{211}\right\} ; & \\
C-C_{210} & =\left\{C_{21}, C_{22}, C_{23}, C_{24}, C_{25}, C_{26}, C_{27}, C_{28}, C_{29},\right. \\
\left.C_{211}\right\} ; & \\
C-C_{211} & =\left\{C_{21}, C_{22}, C_{23}, C_{24}, C_{25}, C_{26}, C_{27}, C_{28}, C_{29},\right. \\
\left.C_{210}\right\} &
\end{aligned}
$$

Since $C_{1 t}, \forall t \in\{2,3,4\}$, is a dispensable attribute we resort to (7) and (13) to compute weights of the suboperational abatement measures and represent the results in Table 4.

$$
\begin{aligned}
& U \backslash C=\left\{\left\{P_{1}\right\},\left\{P_{2}\right\},\left\{P_{3}\right\},\left\{P_{4}\right\},\left\{P_{5}\right\},\left\{P_{6}\right\},\left\{P_{7}\right\},\left\{P_{8}\right\}\right\} \\
& U \backslash C_{21}=\left\{\left\{P_{1}, P_{2}, P_{3}, P_{4}, P_{5}\right\},\left\{P_{7}, P_{8}\right\},\left\{P_{6}\right\}\right\} \\
& U \backslash C_{22}=\left\{\left\{P_{1}, P_{2}, P_{3}, P_{4}, P_{5}, P_{7}\right\},\left\{P_{6}\right\},\left\{P_{8}\right\}\right\}
\end{aligned}
$$




$$
\begin{aligned}
& U \backslash C_{23}=\left\{P_{1}, P_{2}, P_{3}, P_{4}, P_{5}, P_{6}, P_{7}, P_{8}\right\} \\
& U \backslash C_{24}=\left\{\left\{P_{1}, P_{3}, P_{4}, P_{5}, P_{8}\right\},\left\{P_{2}, P_{6}\right\},\left\{P_{7}\right\}\right\} \\
& U \backslash C_{25}=\left\{P_{1}, P_{2}, P_{3}, P_{4}, P_{5}, P_{6}, P_{7}, P_{8}\right\} \\
& U \backslash C_{26}=\left\{\left\{P_{1}, P_{2}, P_{4}, P_{5}, P_{7}, P_{8}\right\},\left\{P_{3}, P_{6}\right\}\right\} \\
& U \backslash C_{27}=\left\{\left\{P_{1}, P_{3}, P_{5}\right\},\left\{P_{2}, P_{6}\right\},\left\{P_{4}, P_{7}, P_{8}\right\}\right\} \\
& U \backslash C_{28}=\left\{\left\{P_{1}, P_{3}, P_{7}, P_{8}\right\},\left\{P_{2}, P_{4}, P_{5}\right\},\left\{P_{6}\right\}\right\} \\
& U \backslash C_{29}=\left\{\left\{P_{1}, P_{3}, P_{4}, P_{5}, P_{7}, P_{8}\right\},\left\{P_{2}\right\},\left\{P_{6}\right\}\right\} \\
& U \backslash C_{210}=\left\{\left\{P_{1}, P_{5}, P_{8}\right\},\left\{P_{2}, P_{7}\right\},\left\{P_{3}\right\},\left\{P_{4}\right\},\left\{P_{6}\right\}\right\} \\
& U \backslash C_{211}=\left\{P_{1}, P_{2}, P_{3}, P_{4}, P_{5}, P_{6}, P_{7}, P_{8}\right\} \\
& U \backslash C-C_{28}=\left\{\left\{P_{1}, P_{5}\right\},\left\{P_{2}\right\},\left\{P_{3}\right\},\left\{P_{4}\right\},\left\{P_{6}\right\},\left\{P_{7}\right\},\left\{P_{8}\right\}\right\} \\
& U \backslash C-C_{2 t}=\left\{\left\{P_{1}\right\},\left\{P_{2}\right\},\left\{P_{3}\right\},\left\{P_{4}\right\},\left\{P_{5}\right\},\left\{P_{6}\right\},\left\{P_{7}\right\},\right. \\
& \left.\quad\left\{P_{8}\right\}\right\}, \quad \forall t \in\{1,2,3,4,5,6,7,9,10,11\} \\
& U \backslash D=\left\{\left\{P_{1}, P_{2}, P_{3}, P_{4}, P_{7}, P_{8}\right\},\left\{P_{5}\right\},\left\{P_{6}\right\}\right\} .
\end{aligned}
$$

Now

$$
\begin{aligned}
\operatorname{POS}_{C-2 t}(D)= & \operatorname{POS}_{C}(D) \\
= & \left\{P_{1}, P_{2}, P_{3}, P_{4}, P_{5}, P_{6}, P_{7}, P_{8}\right\}, \\
& \forall t \in\{1,2,3,4,5,6,7,9,10,11\} .
\end{aligned}
$$

Thus,

$$
\begin{aligned}
& \gamma\left(C-C_{2 t}, D\right)=\gamma(C, D) \longrightarrow \alpha\left(C_{2 t}\right)=0, \\
& \forall t \in\{1,2,3,4,5,6,7,9,10,11\} .
\end{aligned}
$$

Since $C_{2 t}, \forall t \in\{1,2,3,4,5,6,7,9,10,11\}$, is a dispensable attribute we resort to (7) and (13) to compute weights of the subtechnical abatement measures and represent the results in Table 6.

The assessment results in Table 6 indicate that air lubrication, wind power, and solar panels are the more applied technical abatement measures in the Tanzanian shipping sector. On the other hand, hull coating and waste heat reduction are the less applied technical abatement measure.

5.4. Formulation of Rough Assessment Set for GHG Emission Reduction Strategies. We apportion the applied strategies into a vague scale and its corresponding scores. Thus, the assessment set is $V=\left\{V_{1}, V_{2}, V_{3}, V_{4}, V_{5}\right\}=\{$ Very high $(\mathrm{V})$, High $(\mathrm{H})$, Moderate $(\mathrm{M})$, Low $(\mathrm{L})$, Negligible $(\mathrm{N})\}=$ $\{1.00,0.75,0.50,0.25,0.00\}$. Based on Table 4 , we construct a rough set assessment matrix of subfactors corresponding to prime factor 1 (i.e., operational measure) as

$$
\begin{aligned}
& R_{1} \\
& \quad=\left[\begin{array}{llllllll}
0.75 & 1.00 & 0.75 & 1.00 & 0.75 & 1.00 & 1.00 & 0.00 \\
0.75 & 0.75 & 0.50 & 0.00 & 0.25 & 0.75 & 0.75 & 0.75 \\
0.25 & 0.50 & 0.50 & 0.25 & 0.00 & 0.25 & 0.75 & 0.75 \\
0.75 & 0.75 & 0.75 & 0.75 & 0.75 & 1.00 & 0.75 & 0.75
\end{array}\right] .
\end{aligned}
$$

From Table 5, we construct a rough set assessment matrix of subfactors corresponding to prime factor 2 (i.e., technical abatement measure) as

$$
\begin{aligned}
& R_{2} \\
& =\left[\begin{array}{llllllll}
0.00 & 0.00 & 0.00 & 0.00 & 0.00 & 1.00 & 0.00 & 0.00 \\
0.75 & 0.75 & 0.75 & 0.75 & 0.75 & 1.00 & 0.75 & 0.00 \\
0.00 & 0.00 & 0.00 & 0.00 & 0.00 & 0.00 & 0.00 & 0.00 \\
0.75 & 1.00 & 0.75 & 0.75 & 0.75 & 1.00 & 0.00 & 0.75 \\
0.00 & 0.00 & 0.00 & 0.00 & 0.00 & 0.00 & 0.00 & 0.00 \\
0.00 & 0.00 & 0.50 & 0.00 & 0.00 & 0.50 & 0.00 & 0.00 \\
0.50 & 1.00 & 0.50 & 0.75 & 0.50 & 1.00 & 0.75 & 0.75 \\
0.00 & 0.75 & 0.00 & 0.75 & 0.75 & 1.00 & 0.00 & 0.00 \\
0.75 & 0.50 & 0.75 & 0.75 & 0.75 & 1.00 & 0.75 & 0.75 \\
0.75 & 0.00 & 0.50 & 0.25 & 0.75 & 1.00 & 0.00 & 0.75 \\
0.00 & 0.00 & 0.00 & 0.00 & 0.00 & 0.00 & 0.00 & 0.00
\end{array}\right] .
\end{aligned}
$$

5.5. 1st Stage of Two-Stage Rough Set Synthetic Assessment for GHG Emission Reduction Strategies. The first-level assessment is carried out to get the 1st stage of the two-stage rough set synthetic assessment matrix as follows:

$$
E_{1}=A_{1} \cdot R_{1}
$$

where

$$
\begin{aligned}
A_{1} & =(0.41,0.18,0.06,0.35) ; \\
R_{1} & =\left[\begin{array}{lllllllll}
0.75 & 1.00 & 0.75 & 1.00 & 0.75 & 1.00 & 1.00 & 0.00 \\
0.75 & 0.75 & 0.50 & 0.00 & 0.25 & 0.75 & 0.75 & 0.75 \\
0.25 & 0.50 & 0.50 & 0.25 & 0.00 & 0.25 & 0.75 & 0.75 \\
0.75 & 0.75 & 0.75 & 0.75 & 0.75 & 1.00 & 0.75 & 0.75
\end{array}\right] .
\end{aligned}
$$

Thus, $E_{1}=(0.720,0.838,0.690,0.688,0.615,0.910,0.852$, 0.442):

$$
E_{2}=A_{2} \cdot R_{2} \text {, }
$$


where

$$
\begin{aligned}
A_{2}= & (0.05,0.05,0.15, \\
& 0.04,0.15,0.04,0.09,0.11,0.06,0.11,0.15) ; \\
R_{2} & \\
& =\left[\begin{array}{lllllllll}
0.00 & 0.00 & 0.00 & 0.00 & 0.00 & 1.00 & 0.00 & 0.00 \\
0.75 & 0.75 & 0.75 & 0.75 & 0.75 & 1.00 & 0.75 & 0.00 \\
0.00 & 0.00 & 0.00 & 0.00 & 0.00 & 0.00 & 0.00 & 0.00 \\
0.75 & 1.00 & 0.75 & 0.75 & 0.75 & 1.00 & 0.00 & 0.75 \\
0.00 & 0.00 & 0.00 & 0.00 & 0.00 & 0.00 & 0.00 & 0.00 \\
0.00 & 0.00 & 0.50 & 0.00 & 0.00 & 0.50 & 0.00 & 0.00 \\
0.50 & 1.00 & 0.50 & 0.75 & 0.50 & 1.00 & 0.75 & 0.75 \\
0.00 & 0.75 & 0.00 & 0.75 & 0.75 & 1.00 & 0.00 & 0.00 \\
0.75 & 0.50 & 0.75 & 0.75 & 0.75 & 1.00 & 0.75 & 0.75 \\
0.75 & 0.00 & 0.50 & 0.25 & 0.75 & 1.00 & 0.00 & 0.75 \\
0.00 & 0.00 & 0.00 & 0.00 & 0.00 & 0.00 & 0.00 & 0.00
\end{array}\right] .
\end{aligned}
$$

Thus,

$$
\begin{aligned}
E_{2} & =(0.240,0.280,0.232, \\
& 0.290,0.322,0.530,0.150,0.225) .
\end{aligned}
$$

Hence the single factor rough set based assessment matrix is

E

$$
=\left[\begin{array}{llllllll}
0.720 & 0.838 & 0.690 & 0.688 & 0.615 & 0.910 & 0.852 & 0.442 \\
0.240 & 0.280 & 0.232 & 0.290 & 0.322 & 0.530 & 0.150 & 0.225
\end{array}\right] .
$$

5.6. 2nd Stage of Two-Stage Rough Set Synthetic Assessment for the Reduction of GHG Emissions. The multifactor rough set synthetic assessment for the strategies employed by Tanzanian ship investors is given by

$$
\begin{aligned}
& B=A \cdot E^{T} \\
& \text { B } \\
& =\left(\begin{array}{ll}
0.55 & 0.45
\end{array}\right) \\
& \cdot\left[\begin{array}{llllllll}
0.720 & 0.838 & 0.690 & 0.688 & 0.615 & 0.910 & 0.852 & 0.442 \\
0.240 & 0.280 & 0.232 & 0.290 & 0.322 & 0.530 & 0.150 & 0.225
\end{array}\right] \\
& B=\left(\begin{array}{llllllll}
0.504 & 0.587 & 0.484 & 0.509 & 0.483 & 0.739 & 0.536 & 0.344
\end{array}\right) \text {. }
\end{aligned}
$$

The assessment set is composed of the values that represent the applicability of the strategies for GHG emission reduction from the eight interviewed shipping companies. Taking into account that each shipping company has equal chance of applying these reduction strategies, the expected applicability level is given by

$$
E[x]=\sum_{\forall x} x P(X=x) .
$$

Thus,

$$
\begin{aligned}
E[x]= & \frac{1}{8}(50.4 \%)+\frac{1}{8}(58.7 \%)+\frac{1}{8}(48.4 \%) \\
& +\frac{1}{8}(50.9 \%)+\frac{1}{8}(48.3 \%)+\frac{1}{8}(73.9 \%) \\
& +\frac{1}{8}(53.6 \%)+\frac{1}{8}(34.4 \%)=0.52325 .
\end{aligned}
$$

This figure implies that the applicability of both operational and technical abatement measures by the Tanzanian shipping investors for GHG emissions is $52 \%$ (i.e., moderate). The results also reveal the awareness of the Tanzanian shipping investors on the local and international regulations aimed at combating the GHG emission and its disastrous effects (i.e., climate change). Nevertheless, more efforts are needed by all interested parties to give more satisfactory results.

\section{Conclusions}

The shipping industry is currently pressurized to reduce a drastic increase in $\mathrm{CO}_{2}$ emissions which negatively influence the world climate. More specifically, maritime rules and regulations that safeguard the interests of society in this respect, that is, that limit climate change effects of emissions, are likely to emerge in future. Consequently, ship owners and operators will have no choice but to adopt measures that abate emissions from shipping operations. Taking into account the current shipping situation in Tanzania, the viable measures are technical and operational strategies. This study applies RSSA model to assess the landscape of the Tanzanian ship owners and operators on the solution measures to reduce $\mathrm{CO}_{2}$ emissions from shipping operations. The assessment results show that the level of applicability of the abatement measures for GHG emissions is moderate. The results albeit unsatisfactory are promising taking into account the investment capital and financial resources needed to cover the technical abatement measures. Nonetheless, regulators, policy makers, and any other interested parties are called to assist the Tanzanian ship investors in applying the abatement measures to the full. Moreover, the assessment results validate the usefulness of rough set based models in exploratory studies.

\section{Competing Interests}

The authors declare that they have no competing interests.

\section{References}

[1] Det Norske Veritas, "Assessment of measures to reduce future $\mathrm{CO}_{2}$ emissions from shipping," Research and Innovation, Position Paper 05-2010, 2010, http://www.dnv.com.

[2] IPCC, Contribution of Working Group I to the Fourth Assessment Report of the Intergovernmental Panel on Climate Change, 2007, https://www.ipcc.ch/publications_and_data/ar4/wg1/en/contents .html. 
[3] IMO, "Reduction of GHG emissions from ships: third IMO GHG Study 2014," Final Report MEPC 67/INF.3, International Maritime Organization, London, UK, 2014.

[4] IMO, “Second IMO GHG study 2009," MEPC 59/INF.10, International Maritime Organization, London, UK, 2009.

[5] M. S. Eide, O. Endresen, R. Skjong, T. Longva, and S. Alvik, "Cost-effectiveness assessment of $\mathrm{CO}_{2}$ reducing measures in shipping," Maritime Policy and Management, vol. 36, no. 4, pp. 367-384, 2009.

[6] P. Crist, "Greenhouse gas emissions reduction potential from international shipping," in Proceedings of the International Transport Forum, Leipzig, Germany, 2009.

[7] J. J. Corbett, H. Wang, and J. J. Winebrake, "The effectiveness and costs of speed reductions on emissions from international shipping," Transportation Research Part D: Transport and Environment, vol. 14, no. 8, pp. 593-598, 2009.

[8] IMO, "Prevention of air pollution from ships: proposal to establish a vessel efficient system submitted by World Shipping Council," Tech. Rep. MEPC60, International Maritime Organization, London, UK, 2010.

[9] J. Blasco, V. Durán-Grados, M. Hampel, and J. MorenoGutiérrez, "Towards an integrated environmental risk assessment of emissions from ships' propulsion systems," Environment International, vol. 66, pp. 44-47, 2014.

[10] H. Lindstad, B. E. Asbjørnslett, and A. H. Strømman, "The importance of economies of scale for reductions in greenhouse gas emissions from shipping," Energy Policy, vol. 46, pp. 386398, 2012.

[11] J. Moreno-Gutiérrez, F. Calderay, N. Saborido, M. Boile, R. Rodríguez Valero, and V. Durán-Grados, "Methodologies for estimating shipping emissions and energy consumption: a comparative analysis of current methods," Energy, vol. 86, pp. 603-616, 2015.

[12] H. Lindstad, B. E. Asbjørnslett, and A. H. Strømman, "Reductions in greenhouse gas emissions and cost by shipping at lower speeds," Energy Policy, vol. 39, no. 6, pp. 3456-3464, 2011.

[13] A. Maragkogianni and S. Papaefthimiou, "Evaluating the social cost of cruise ships air emissions in major ports of Greece," Transportation Research Part D: Transport and Environment, vol. 36, pp. 10-17, 2015.

[14] V. Eyring, I. S. A. Isaksen, T. Berntsen et al., "Transport impacts on atmosphere and climate: shipping," Atmospheric Environment, vol. 44, no. 37, pp. 4735-4771, 2010.

[15] P. Zhou and H. Wang, "Carbon capture and storagesolidification and storage of carbon dioxide captured on ships," Ocean Engineering, vol. 91, pp. 172-180, 2014.

[16] V. N. Armstrong, "Vessel optimisation for low carbon shipping," Ocean Engineering, vol. 73, pp. 195-207, 2013.

[17] H. Winnes, L. Styhre, and E. Fridell, "Reducing GHG emissions from ships in port areas," Research in Transportation Business \& Management, vol. 17, pp. 73-82, 2015.

[18] M. Kitada and A. Ölcer, "Managing people and technology: the challenges in CSR and energy efficient shipping," Research in Transportation Business \& Management, vol. 17, pp. 36-40, 2015.

[19] C.-C. Chang and C.-M. Wang, "Evaluating the effects of speed reduce for shipping costs and $\mathrm{CO}_{2}$ emission," Transportation Research Part D: Transport and Environment, vol. 31, pp. 110115, 2014.

[20] N. Heitmann and S. Khalilian, "Accounting for carbon dioxide emissions from international shipping: burden sharing under different UNFCCC allocation options and regime scenarios," Marine Policy, vol. 35, no. 5, pp. 682-691, 2011.
[21] Y. H. V. Lun, K.-H. Lai, C. W. Y. Wong, and T. C. E. Cheng, "Environmental governance mechanisms in shipping firms and their environmental performance," Transportation Research Part E: Logistics and Transportation Review, vol. 78, pp. 82-92, 2015.

[22] R. T. Poulsen, S. Ponte, and J. Lister, "Buyer-driven greening? Cargo-owners and environmental upgrading in maritime shipping," Geoforum, vol. 68, pp. 57-68, 2016.

[23] H. Lindstad, R. M. Bright, and A. H. Strømman, "Economic savings linked to future Arctic shipping trade are at odds with climate change mitigation," Transport Policy, vol. 45, pp. 24-30, 2016.

[24] J. Calleya, R. Pawling, and A. Greig, "Ship impact model for technical assessment and selection of Carbon dioxide Reducing Technologies (CRTs)," Ocean Engineering, vol. 97, pp. 82-89, 2015.

[25] N. Heitmann and S. Peterson, "The potential contribution of the shipping sector to an efficient reduction of global carbon dioxide emissions," Environmental Science \& Policy, vol. 42, pp. 56-66, 2014.

[26] Y. B. Shi, "Reducing greenhouse gas emissions from international shipping: is it time to consider market-based measures?" Marine Policy, vol. 64, pp. 123-134, 2016.

[27] S. D. Chatzinikolaou and N. P. Ventikos, "Holistic framework for studying ship air emissions in a life cycle perspective," Ocean Engineering, vol. 110, pp. 113-122, 2015.

[28] R. Lu, O. Turan, E. Boulougouris, C. Banks, and A. Incecik, "A semi-empirical ship operational performance prediction model for voyage optimization towards energy efficient shipping," Ocean Engineering, vol. 110, pp. 18-28, 2015.

[29] X. Qi and D.-P. Song, "Minimizing fuel emissions by optimizing vessel schedules in liner shipping with uncertain port times," Transportation Research Part E: Logistics and Transportation Review, vol. 48, no. 4, pp. 863-880, 2012.

[30] A. Miola and B. Ciuffo, "Estimating air emissions from ships: meta-analysis of modelling approaches and available data sources," Atmospheric Environment, vol. 45, no. 13, pp. 22422251, 2011.

[31] J. S. L. Lam and K.-H. Lai, "Developing environmental sustainability by ANP-QFD approach: the case of shipping operations," Journal of Cleaner Production, vol. 105, pp. 275-284, 2015.

[32] J. Z. Ren and M. Lützen, "Fuzzy multi-criteria decision-making method for technology selection for emissions reduction from shipping under uncertainties," Transportation Research Part D: Transport and Environment, vol. 40, pp. 43-60, 2015.

[33] S. A. Mansouri, H. Lee, and O. Aluko, "Multi-objective decision support to enhance environmental sustainability in maritime shipping: a review and future directions," Transportation Research Part E: Logistics and Transportation Review, vol. 78, pp. 3-18, 2015.

[34] J. W. Grzymala-Busse, "Rough set strategies to data with missing attribute values," in Proceedings of the 3rd International Conference on Data Mining, pp. 56-63, Melbourne, Fla, USA, November 2003.

[35] Z. Suraj, "An introduction to rough set theory and its applications: a tutorial," in Proceedings of the 1st International Computer Engineering Conference (ICENCO '04), Cairo, Egypt, December 2004.

[36] Det Norske Veritas, "Project Final Report on the Assessment of IMO mandated energy efficiency measures for international shipping: estimated $\mathrm{CO}_{2}$ emissions reduction from introduction of mandatory technical and operational energy efficiency 
measures for ships,” MEPC 63/INF.2, International Maritime Organization, London, UK, 2011.

[37] International Maritime Organization (IMO), "Reduction of GHG emissions from ships: marginal abatement costs and cost-effectiveness of energy-efficiency measures," Tech. Rep. MEPC 61/INF.18, International Maritime Organization (IMO), London, UK, 2010. 


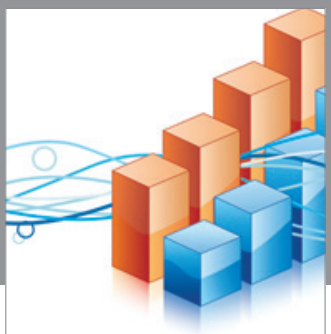

Advances in

Operations Research

vatem alat4

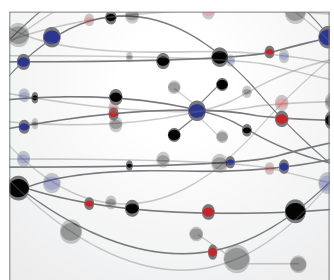

\section{The Scientific} World Journal
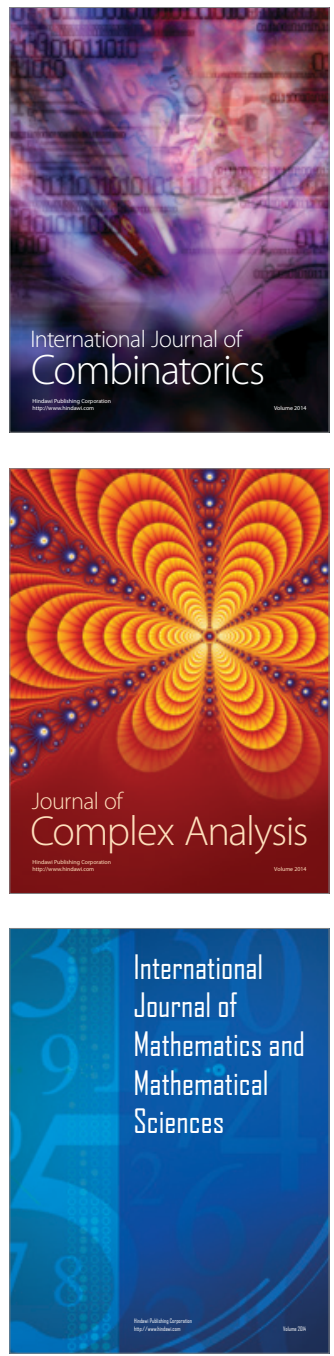
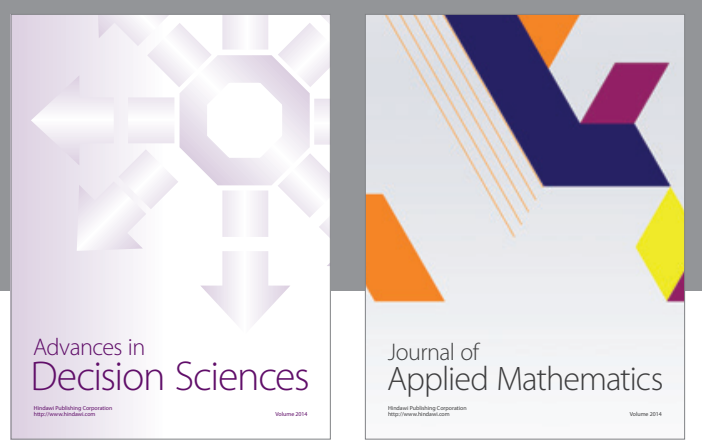

Algebra

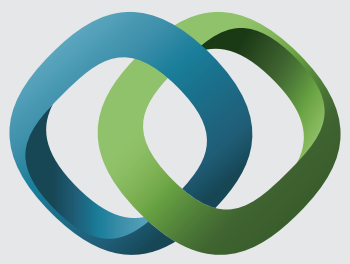

\section{Hindawi}

Submit your manuscripts at

http://www.hindawi.com
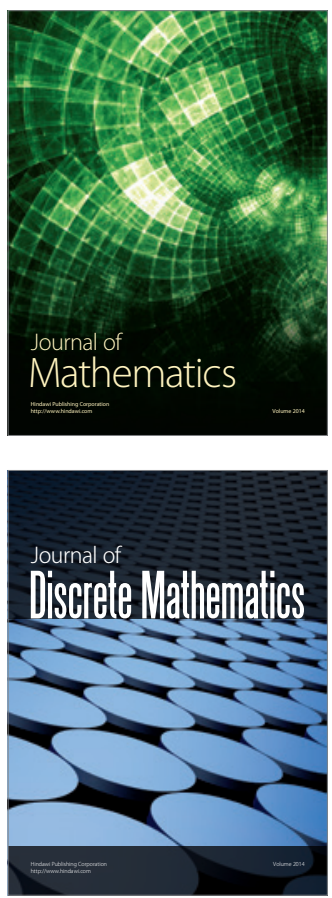

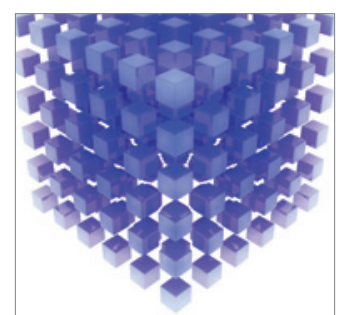

Mathematical Problems in Engineering
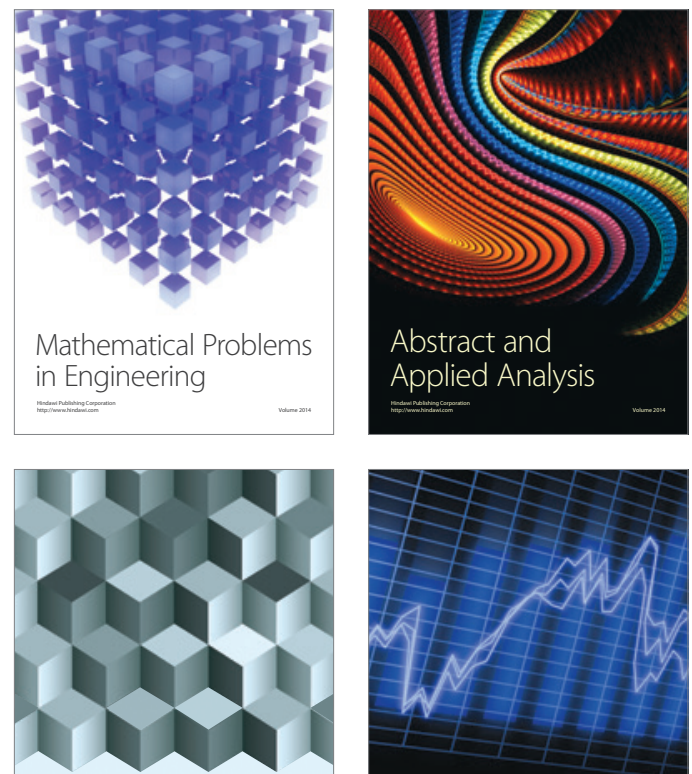

Journal of

Function Spaces

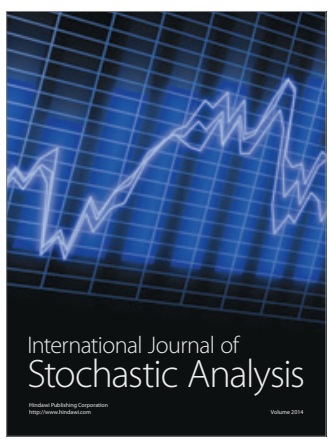

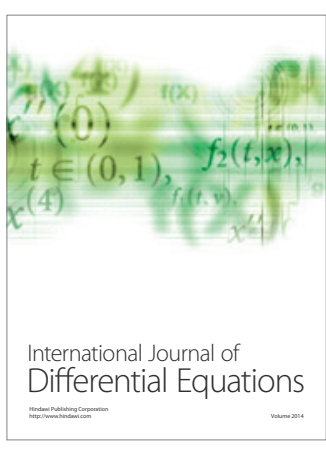
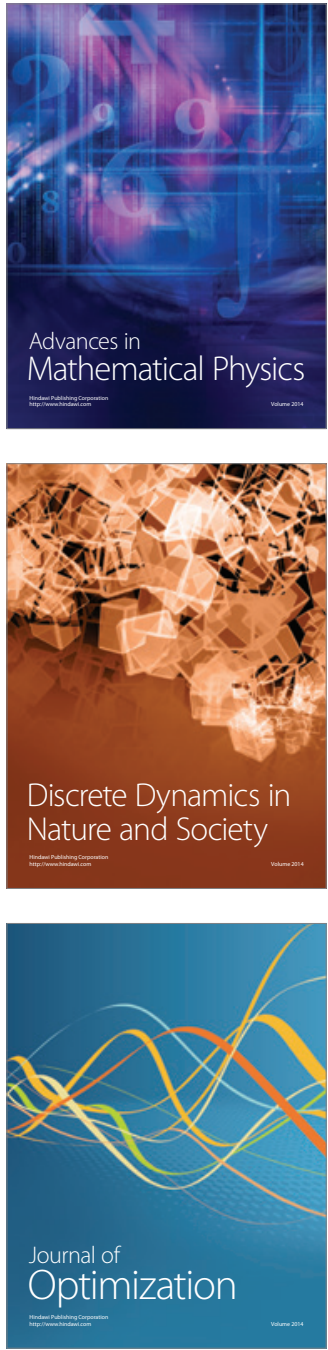